\title{
Modifier genes for disorders of thrombosis and hemostasis
}

\author{
R. J. WESTRICK* and D. GINSBURG $\dagger$ \\ *Department of Human Genetics, University of Michigan, Ann Arbor, Ml; and †Departments of Internal Medicine and Human Genetics, Howard \\ Hughes Medical Institute, Life Sciences Institute, University of Michigan, Ann Arbor MI, USA
}

To cite this article: Westrick RJ, Ginsburg D. Modifier genes for disorders of thrombosis and hemostasis. J Thromb Haemost 2009; 7 (Suppl. 1): 132-5.

\begin{abstract}
Summary. Most inherited hemostatic disorders exhibit incomplete penetrance and variable expressivity, which can be because of genetic or environmental interactions. This wide phenotypic variability for a given disease can be partly explained by modifier gene interactions. Modifier gene interactions have been described for VWD, TTP and venous thrombosis associated with the factor $\mathrm{V}$ Leiden mutation. We have exploited advances in mouse genetics in an effort to identify novel genetic loci that may serve as candidate genetic modifiers for bleeding and thrombosis in humans. We have identified several loci affecting plasma VWF levels and have identified and characterized mouse models of ADAMTS13 deficiency and Factor V Leiden that could be useful for identifying novel genes contributing to thrombosis risk in humans.
\end{abstract}

Keywords: ADAMTS13, factor V Leiden, genetic model, hemostasis, mice, von Willebrand factor.

\section{Introduction}

The development of a pressurized vertebrate vascular system is a recent event in evolution to efficiently supply oxygen and nutrients to every cell. Maintaining both the integrity and patency of this type of vascular system is essential for the viability of the organism. These functions were provided by the evolution of the vertebrate hemostatic system [1]. Although it contains numerous controls to ensure operation within the 'normal' range, hemostasis is nevertheless sensitive to perturbation by both genetic and environmental factors. (Fig. 1).

Elucidation of the components of the coagulation cascade and their role in regulating hemostatic balance has come in large part from the study of human patients with inherited bleeding or thrombotic diseases [2]. Wide variation in the severity of bleeding or thrombosis among patients with the

Correspondence: D. Ginsburg, Departments of Internal Medicine and Human Genetics, Howard Hughes Medical Institute, 5428 Life Sciences Institute, University of Michigan, 210 Washtenaw Avenue, Ann Arbor, MI 48109, USA.

Tel.: 734647 4808; fax: 7349362888 .

E-mail: ginsburg@umich.edu same disorder can be attributed to genetic or environmental interactions and manifests as either incomplete penetrance or variable expressivity [3]. Incomplete penetrance results when not every member of a population inheriting a particular disease genotype also exhibits the disease phenotype. Differences in the range of symptoms and severity among patients with the same disease is referred to as variable expressivity.

A modifier gene is an inherited genetic variation which leads to a qualitative or quantitative difference in any aspect of the disease phenotype [4]. Modifier gene interactions have been described for von Willebrand disease (VWD), thrombotic thrombocytopenic purpura (TTP) and venous thrombosis associated with the factor V Leiden (FVL) mutation [3]. We and others have exploited advances in mouse genetics in an effort to identify novel genetic loci that may serve as candidate genetic modifiers for bleeding and thrombosis in humans [5-10].

\section{Identifying modifier genes of plasma VWF levels in the mouse}

Inbred mouse strains exhibit considerable naturally-occurring genotypic and phenotypicvariations. Some of the most divergent mouse strains are more distantly related to each other than are humans to chimpanzees [11]. Inbred mouse strains have been shown to differ markedly in many hematologic parameters, including VWF levels, susceptibility to bleeding and clinical assessments of blood coagulation such as the prothrombin time (PT) and activated partial thromboplastin time (APTT) $[5,12,13]$. In addition, specific thrombotic mouse models often display varying phenotypes in different genetic strain backgrounds [7,10]. For example, the wild-derived castaneous mouse (CASA/RkJ) exhibits a ten- to twenty-fold higher plasma VWF levels as compared with other inbred strains $[13,14]$.

Through a series of genetic crosses using the CASA/RkJ and RIIIS/J mouse strains, we identified a modifier locus (Mvwf1) responsible for low plasma VWF levels [13]. Mvwf1 controls the expression of a glycosyltransferase gene called B4galnt2 (previously termed Galgt2). B4galnt2 is expressed in the endothelium in the RIIIS/J mouse, whereas it is expressed 


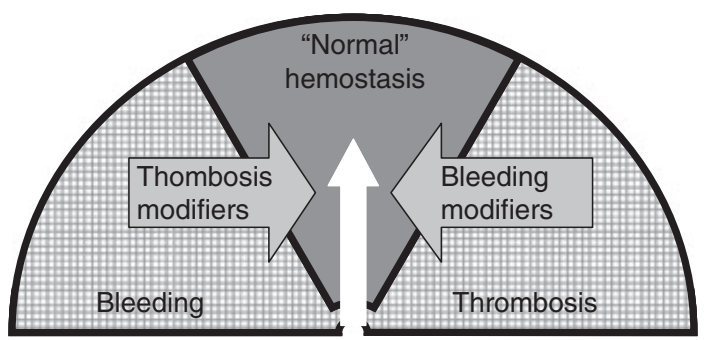

Fig. 1. Thrombotic potential of the coagulation system. With minor fluctuations, the system is designed to operate in the 'normal' (gray) range, as indicated by the white gauge arrow. Genetic modifier genes either reducing or increasing (light gray arrows) the thrombotic potential of the system will cause systemic malfunction (hatched zones), where there is a heightened susceptibility to either bleeding or thrombosis.

primarily in intestinal epithelium in most other mouse strains (and in humans). Endothelial expression of B4galnt2 results in altered glycosylation of VWF, leading to accelerated clearance from the circulation [15]. The Mvwfl locus was initially localized to a $300 \mathrm{~Kb}$ region upstream of the B4galnt2 gene $[13,15]$. Subsequent analysis of a number of additional inbred strains narrowed the $M v w f 1$ region to a $30 \mathrm{~Kb}$ haplotype block [16]. The $M v w f 1$ allele is also present in a number of wildcaught mice, suggesting that this locus may be under evolutionary selection in the wild, although the source of the corresponding selective pressure is still unknown [17].

To identify additional genes contributing to the variability of murine VWF, plasma levels were surveyed in additional mouse strains. A/J was identified as a strain with low VWF levels that are independent of the influence of the $M v w f 1$ allele [9]. Genomic analysis of F2 mice derived from an A/J X CASA/ $\mathrm{RkJ}$ cross identified three additional strain modifier loci (Mvwf2-4) responsible for variation in plasma VWF level. The major modifier, $M v w f 2$, mapped to the $V w f$ locus itself on chromosome 6. A non-synonymous amino acid substitution (R2657Q) on the CASA/RkJ $V w f$ allele results in significantly increased VWF biosynthesis in vitro. The Mvwf2 locus accounts for approximately $16 \%$ of the variation in plasma VWF levels observed between the $\mathrm{A} / \mathrm{J}$ and CASA/RkJ strains [9].

Using a higher density marker scan and quantitative trait loci (QTL) analysis, $M v w f 3$ and $M v w f 4$ were identified from the same genetic cross as loci, which also contribute to the genetic regulation of plasma VWF levels. These loci exert effects primarily contingent upon being homozygous for the CASA/RkJ $V w f$ alleles, suggesting epistatic interactions between these modifiers and the $V w f$ locus. Interestingly, $M v w f 3$ and $M v w f 4$ exhibit conservation of synteny with regions on human chromosomes 1, 5 and 6 identified by the GAIT study [8]. Conserved synteny involves two or more genes being grouped in a specific chromosomal region in one species, and also being grouped in an equivalent chromosomal region in another species [18]. These data suggest that orthologs of gene(s) within the $M v w f 3$ and $M v w f 4$ candidate intervals may also be relevant as modifiers of plasma VWF in humans.

\section{Strain-specific modifier loci in the ADAMTS13-deficient mouse}

Deficiency of ADAMTS13 caused by autoantibodies is responsible for most cases of acquired TTP, whereas genetic mutation in the ADAMTS13 gene is the major cause of familial TTP [19]. Incomplete penetrance is evident in familial TTP, with some patients presenting in the neonatal period, and with others, often in the same family, not identified until late childhood or adulthood. In addition, patients with the same ADAMTS13 mutation can demonstrate considerable variability in disease severity.

Mice homozygous-deficient for ADAMTS13 exhibit no signs of TTP-like disease on the $\mathrm{C} 57 \mathrm{Bl} / 6 \mathrm{~J}$ genetic background [20]. However, when ADAMTS13-deficient mice were analyzed on a mixed $\mathrm{C} 57 \mathrm{Bl} / 6 \mathrm{~J}-\mathrm{CASA} / \mathrm{RkJ}$ genetic background, a subset exhibited spontaneous thrombocytopenia and histologic findings resembling human TTP. Similar findings could be induced in the majority of mixed background ADAMTS13deficient mice administered with shigatoxin, though no changes were observed in ADAMTS13-deficient mice on the C57Bl/6J genetic background. These data suggest the existence of strain-specific modifier gene(s) in the CASA/RkJ strain that act as a susceptibility factor for either spontaneous or shiga-toxin-induced TTP in the setting of ADAMTS13 deficiency [20]. Identification of the specific underlying genes could provide important insight into the pathogenesis of human TTP.

\section{Utilizing the Factor V Leiden mouse model to identify thrombosis modifiers}

Similar to VWD and TTP, predisposition to venous thrombosis can be heavily influenced by mutations in a single gene and/ or combinations of genes. Venous thrombosis has been hypothesized to be oligogenic [21] with a handful of genetic variants in various combination(s) contributing to the risk [22], although many of these remain to be identified.

FVL is the most common inherited risk factor for venous thrombosis, with an allele frequency of approximately 0.025 in European-derived populations [2]. FVL is estimated to account for up to 25 percent of the genetically-attributable thrombosis risk in humans [23]. However, penetrance is low, with only $10 \%$ of FVL heterozygotes and $80 \%$ of homozygotes developing thrombosis in their lifetimes. The severity of thrombosis also varies widely among affected individuals [2].

The incomplete penetrance and variable expressivity of clinical thrombosis among FVL patients can at least partially be explained by genetic interactions between FVL and other known thrombotic risk factors, such as heterozygous deficiency of antithrombin III, protein C or protein S, as well as the common prothrombin 20210 polymorphism [2]. However, less than $2 \%$ of FVL heterozygotes would be expected to co-inherit one or more of these risk factors, suggesting that a large number of additional genetic variants interacting with FVL that may increase or decrease susceptibility to thrombosis are 
yet to be identified. However, recent genetic studies in human thrombosis patients (with or without FVL) have failed to provide convincing evidence for identifying additional novel thrombosis susceptibility genes or genetic modifiers of FVL $[21,23,24]$.

Mice carrying the ortholog of the human FVL mutation exhibit a mild-to-moderate prothrombotic phenotype, closely resembling the human disorder, with a similarly more severe thrombosis in homozygotes [25]. Not surprisingly, genetic interactions have been observed in FVL mice. In the initial report, an interaction of the $129 \mathrm{~Sv}$ mouse strain with homozygous FVL was observed, with an approximately $30 \%$ mortality observed on the 129 strain background [25]. A synthetic lethal interaction between FVL homozygosity $\left(\mathrm{FV}^{\mathrm{Q} / \mathrm{Q}}\right)$ and heterozygosity for tissue factor pathway inhibitor $\left(\mathrm{TFPI}^{+/-}\right.$) was also observed, with nearly all mice with this lethal genotype combination $\left(\mathrm{FV}^{\mathrm{Q} / \mathrm{Q}} \mathrm{TFPI}^{+/-}\right)$ succumbing to widespread, systemic thrombosis in the immediate perinatal period on the $\mathrm{C} 57 \mathrm{Bl} / 6 \mathrm{~J}$ genetic background [26].

Mutagenesis screens provide a powerful tool for the dissection of molecular pathways in vivo, and have long been used as a standard tool in model organisms including $C$. elegans, D. melanogaster and D. rerio. Similar approaches have also been successfully applied in mice to explore genetic networks regulating a variety of processes, including coat color [27], hearing [28], circadian rhythm [29], and the innate immune response [30]. N-ethyl $\mathrm{N}$-nitrosourea (ENU) is generally the mutagenic agent of choice, inducing germline mutations at a rate ten- to fifteen-fold greater than the endogenous background in untreated mice [30].

A variation of the ENU mutagenesis approach employs a genetic, chemical, or environmental sensitizer to focus on a specific phenotype of interest. For example, a recent mutagenesis screen in thrombopoietin receptor-deficient mice uncovered a previously unappreciated role of the c-Myb gene as a dominant modifier of circulating platelet number [31].

We are using the synthetic lethality of the $\mathrm{FV}^{\mathrm{Q} / \mathrm{Q}} \mathrm{TFPI}^{+/-}$ genotype as a phenotypic screen for thrombosis modifier genes [3]. Thus, this screen is dependent upon the lethality associated with $\mathrm{FV}^{\mathrm{Q} / \mathrm{Q}} \mathrm{TFPI}^{+/-}$genotype and aims to find coagulation modifier genes that lessen the severity of thrombosis in these mice, thereby restoring viability to mice carrying the $\mathrm{FV} Q / \mathrm{Q}$ $\mathrm{TFPI}^{+/-}$genotype. It is hoped that this screen will identify a large subset of dominantly acting genes encoding critical regulators of hemostasis. Common polymorphisms in these genes could explain a significant portion of the incomplete penetrance and variable expressivity among human patients with factor V Leiden.

In summary, we have used animal models to identify genetic loci influencing plasma VWF factors. In addition, we have identified and characterized animal models of ADAMTS13 deficiency and Factor V Leiden that could be useful for identifying novel genes/genetic modifiers contributing to thrombosis risk. Any genetic variants isolated in these studies should provide new insights into the overall regulation of hemostasis and facilitate the development of future novel therapeutic interventions.

\section{Disclosure of Conflict of interests}

The authors declare no conflict of Interest.

\section{References}

1 Davidson CJ, Tuddenham EG, McVey JH. 450 million years of hemostasis. J Thromb Haemost 2003; 1: 1487-94.

2 Ginsburg D. Hemophilia and Other Disorders of Hemostasis. Emery and Rimoin's Principles and Practice of Medical Genetics, 5th edn. New York: Churchill Livingstone, 2007.

3 Ginsburg D. Identifying novel genetic determinants of hemostatic balance. J Thromb Haemost 2005; 3: 1561-8.

4 Houlston RS, Tomlinson IP. Modifier genes in humans: strategies for identification. Eur J Hum Genet 1998; 6: 80-8.

5 Hoover-Plow JL, Shchurin A, Hart E, Sha J, Singer JB, Hill AE, Nadeau JH. Genetic background determines response to hemostasis and thrombosis. BMC Blood Disord 2006; 6: 6.

6 Sa Q, Hart E, Hill AE, Nadeau JH, Hoover-Plow JL. Quantitative trait locus analysis for hemostasis and thrombosis. Mamm Genome 2008; 19: 406-12.

7 Rosen ED, Xuei X, Suckow M, Edenberg H. Searching for hemostatic modifier genes affecting the phenotype of mice with very low levels of FVII. Blood Cells Mol Dis 2006; 36: 131-4.

8 Lemmerhirt HL, Broman KW, Shavit JA, Ginsburg D. Genetic regulation of plasma von Willebrand factor levels: QTL analysis in a mouse model. J Thromb Haemost 2006; 5: 329-35.

9 Lemmerhirt HL, Shavit JA, Levy GG, Cole SM, Long JC, Ginsburg D. Enhanced VWF biosynthesis and elevated plasma VWF due to a natural variant in the murine Vwf gene. Blood 2006; 108: 3061-7.

10 Westrick RJ, Winn ME, Eitzman DT. Murine models of vascular thrombosis. Arterioscler Thromb Vasc Biol 2007; 27: 2079-93.

11 Frazer KA, Eskin E, Kang HM, Bogue MA, Hinds DA, Beilharz EJ, Gupta RV, Montgomery J, Morenzoni MM, Nilsen GB, Pethiyagoda CL, Stuve LL, Johnson FM, Daly MJ, Wade CM, Cox DR. A sequence-based variation map of 8.27 million SNPs in inbred mouse strains. Nature 2007; 448: 1050-3.

12 Peters LL, Zhang W, Lambert AJ, Brugnara C, Churchill GA, Platt OS. Quantitative trait loci for baseline white blood cell count, platelet count, and mean platelet volume. Mamm Genome 2005; 16: 749-63.

13 Mohlke KL, Nichols WC, Westrick RJ, Novak EK, Cooney KA, Swank RT, Ginsburg D. A novel modifier gene for plasma von Willebrand factor level maps to distal mouse chromosome 11. Proc Natl Acad Sci USA 1996; 93: 15352-7.

14 Sweeney JD, Novak EK, Reddington M, Takeuchi KH, Swank RT. The RIIIS/J inbred mouse strain as a model for von Willebrand disease. Blood 1990; 76: 2258-65.

15 Mohlke KL, Purkayastha AA, Westrick RJ, Smith PL, Petryniak B, Lowe JB, Ginsburg D. Mvwf, a dominant modifier of murine von Willebrand factor, results from altered lineage-specific expression of a glycosyltransferase. Cell 1999; 96: 111-20.

16 Johnsen JM, Levy GG, Westrick RJ, Tucker PK, Ginsburg D. The endothelial-specific regulatory mutation, Mvwf1, is a common mouse founder allele. Mamm Genome 2008; 19: 32-40.

17 Johnsen JM, Teschke M, Pavlidis P, McGee BM, Tautz D, Ginsburg D, Baines JF. Selection on cis-regulatory variation at B4galnt2 and its influence on von Willebrand Factor in house mice. Mol Biol Evol 2008; 26: $567-78$.

18 Wright MW, Bruford EA. Human and orthologous gene nomenclature. Gene 2006; 369: 1-6. 
19 Levy GG, Motto DG, Ginsburg D. ADAMTS13 turns 3. Blood 2005; 106: $11-7$.

20 Motto DG, Chauhan AK, Zhu G, Homeister J, Lamb CB, Desch KC, Zhang W, Tsai HM, Wagner DD, Ginsburg D. Shigatoxin triggers thrombotic thrombocytopenic purpura in genetically susceptible ADAMTS13-deficient mice. J Clin Invest 2005; 115: 2752-61.

21 Bertina RM. Genetic approach to thrombophilia. Thromb Haemost 2001; 86: 92-103.

22 Bertina RM. Molecular risk factors for thrombosis. Thromb Haemost 1999; 82: 601-9.

23 Souto JC, Almasy L, Borrell M, Blanco-Vaca F, Mateo J, Soria JM, Coll I, Felices R, Stone W, Fontcuberta J, et al. Genetic susceptibility to thrombosis and its relationship to physiological risk factors: the GAIT study. Genetic Analysis of Idiopathic Thrombophilia. Am J Hum Genet 2000; 67: 1452-9.

24 Bezemer ID, Bare LA, Doggen CJ, Arellano AR, Tong C, Rowland CM, Catanese J, Young BA, Reitsma PH, Devlin JJ, et al. Gene variants associated with deep vein thrombosis. JAMA 2008; 299: 130614.

25 Cui J, Eitzman DT, Westrick RJ, Christie PD, Xu ZJ, Yang AY, Purkayastha AA, Yang TL, Metz AL, Gallagher KP, et al. Spontaneous thrombosis in mice carrying the factor V Leiden mutation. Blood 2000; 96: 4222-6.
26 Eitzman DT, Westrick RJ, Bi X, Manning SL, Wilkinson JE, Broze GJ, Ginsburg D. Lethal perinatal thrombosis in mice resulting from the interaction of tissue factor pathway inhibitor deficiency and factor V Leiden. Circulation 2002; 105: 2139-42.

27 Tsipouri V, Curtin JA, Nolan PM, Vizor L, Parsons CA, Clapham CM, Latham ID, Rooke LJ, Martin JE, Peters J, et al. Three Novel Pigmentation Mutants Generated by Genome-Wide Random ENU Mutagenesis in the Mouse. Comp Funct Genomics 2004; 5: 123-7.

28 Hardisty RE, Erven A, Logan K, Morse S, Guionaud S, SanchoOliver S, Hunter AJ, Brown SD, Steel KP. The deaf mouse mutant Jeff (Jf) is a single gene model of otitis media. $J$ Assoc Res Otolaryngol 2003; 4: 130-8.

29 Vitaterna MH, King DP, Chang AM, Kornhauser JM, Lowrey PL, McDonald JD, Dove WF, Pinto LH, Turek FW, Takahashi JS. Mutagenesis and mapping of a mouse gene, Clock, essential for circadian behavior. Science 1994; 264: 719-25.

30 Beutler B, Du X, Xia Y. Precis on forward genetics in mice. Nat Immunol 2007; 8: 659-64.

31 Carpinelli MR, Hilton DJ, Metcalf D, Antonchuk JL, Hyland CD, Mifsud SL, Di Rago L, Hilton AA, Willson TA, Roberts AW, et al. Suppressor screen in $\mathrm{Mpl}-/-$ mice: $\mathrm{c}-\mathrm{Myb}$ mutation causes supraphysiological production of platelets in the absence of thrombopoietin signaling. Proc Natl Acad Sci USA 2004; 101: 6553-8. 